showed a statistically significance difference in screening rates $(p<0.05)$. These results suggest that outreach to rural primary care practices can be effective in increasing screening for colorectal cancer.

\section{P2-63 HOW SOCIO-CULTURAL AND RELIGIOUS BELIEFS INFLUENCE ATTITUDES OF IRANIAN RECIPIENT COUPLES TOWARDS ASSISTED REPRODUCTIVE DONATION PROCEDURES}

doi:10.1136/jech.2011.142976h.98

${ }^{1} \mathrm{R}$ L Roudsari, ${ }^{*} \mathrm{H}$ Jafari, ${ }^{2} \mathrm{~A}$ Taghipour, ${ }^{3} \mathrm{~N}$ Khadem, ${ }^{4} \mathrm{~S}$ Ebrahimzadeh. ${ }^{1}$ Mashhad University of Medical Sciences, Department of Midwifery, Mashhad, Khorasan Razavi, Iran; ${ }^{2}$ Mashhad University of Medical Sciences, Department of Biostatistics \& Epidemiology, Mashhad, Khorasan Razavi, Iran; ${ }^{3}$ Mashhad University of Medical Sciences, Department of Obstetrics \& Gynecology, Mashhad, Khorasan Razavi, Iran; ${ }^{4}$ Mashhad University of Medical Sciences, Department of Public Health, Mashhad, Khorasan Razavi, Iran

Introduction The revolutionary advance in the field of reproductive technologies has created controversial sociological, cultural, religious, moral and legal issues. Considering the potential impact of these complex issues on the practice of reproductive technologies, this study aimed to investigate how socio-cultural and religious beliefs influence attitudes of recipient couples towards assisted reproductive donation procedures in an Iranian population.

Methods This correlational study was carried out on 60 male and female with primary infertility who referred to the Montaserieh Infertility Research Center in Mashhad and used donated egg, embryo or uterus and were selected using convenience sampling. Socio-cultural and religious beliefs, attitudes and knowledge of infertile couples towards donation procedures were measured using valid and reliable self structured questionnaires. Data were analysed using T test, one way ANOVA and Pearson' correlation coefficient.

Results There was a direct correlation between socio-cultural $(p<0.001)$ and religious beliefs $(p<0.001)$ of recipients with their attitudes towards donation procedures, that is, people with more positive socio-cultural and religious beliefs had higher degree of acceptance towards donation procedures. A direct correlation also was found between socio-cultural beliefs and couples' knowledge $(p<0.001)$ and also their place of residence $(p<0.001)$. An indirect correlation was found between socio-cultural beliefs and infertility length $(p<0.017)$ and the duration of treatment $(p<0.009)$.

Conclusion Promotion of social-cultural and religious beliefs at the community level may endorse positive attitudes in infertile couples which could provide appropriate bases for the decision made by infertile couples in an environment free from tension and fear of the wrong beliefs.

\section{P2-64 ABSOLUTE RISK CHARTS FOR DEATH WITHIN 10 YEARS FOR AUSTRALIAN IN THEIR 70'S BY BEHAVIOURAL RISK FACTORS}

doi:10.1136/jech.2011.142976h.99

${ }^{1} \mathrm{~A}$ Dobson, ${ }^{1} \mathrm{~W}$ Brown, ${ }^{2} \mathrm{G}$ Hankey, ${ }^{2} \mathrm{O}$ Almeida, ${ }^{3} \mathrm{~J}$ Byles, ${ }^{2} \mathrm{D}$ McLaughlin, ${ }^{1} \mathrm{~J}$ Leung, ${ }^{2} \mathrm{~K}$ McCaul, ${ }^{2} \mathrm{~L}$ Flicker. ${ }^{1}$ University of Queensland, Brisbane, Australia; ${ }^{2}$ University of Western Australia, Perth, Australia; ${ }^{3}$ University of Newcastle, Newcastle, Australia

Introduction Demographic changes and increasing life expectancy in developed countries mean that ever increasing numbers of people will live into their 70s. These individuals, their families and healthcare providers, and healthcare policy makers will be seeking valid, yet simple, information that helps them predict their longterm mortality and how their risk may be reduced. Increasing age and health-related behaviours, such as smoking and physical activity, are major modifiable determinants of long-term mortality. We aimed to develop a valid, user-friendly colour-coded chart of absolute risk of death for elderly men and women in Australia.

Methods Data were from people aged 71-79 participating in the Australian Longitudinal Study on Women's Health (national sample, $\mathrm{n}=7438$ ) and the Health in Men Study (Perth, Western Australia, $\mathrm{n}=6053$ ). Logistic regression models were fitted for each sex separately with age, level of physical activity, body mass index and smoking as explanatory variables. The expected proportion of deaths within 10 years for each combination of explanatory variables was estimated.

Results The risks of death were high, all exceeding $10 \%$ for women and $20 \%$ for men. Risks were substantially higher for men than women. For both sexes risk was highest in the oldest age group among smokers who reported little or no physical activity.

Conclusions The risk charts we have developed provide a tool for clinicians to explain to their patients the risks (and benefits) of health related behaviours for older people in the context of the substantial effects of age and sex.

\section{P2-65 IMPACT OF ACCULTURATION ON CORONARY ARTERY DISEASE IN THE SOUTH ASIAN IMMIGRANTS- UNIQUE POPULATION WITH INCREASED RISK}

doi:10.1136/jech.2011.142976h.100

S Dodani, ${ }^{*}$ L Dong. University of Kansas Medical Center, Leawood, USA

Although differences in coronary artery disease (CAD) risk factors between immigrants and non-immigrants have been examined previously, the effect of acculturation on $\mathrm{CAD}$ risk factors in immigrants has not been fully studied less well studied. The aim of this study is to measure the level of acculturation and its association with CAD and other factors, including Type 2 Diabetes (T2D) in South Asian immigrants.

Methods Using an epidemiologic cross-sectional study design, 161 South Asian immigrants between the ages of 35-65 years were randomly recruited from the US States. CAD markers and common carotid artery intima media thickness (CCA-IMT) were assessed. Scaled (The Suinn-Lew Asian Self-Identity Acculturation scale-SLASIA Scale) and non-scaled ( $\geq 10$ years stay in the US) methods were used to measure the acculturation status.

Results Of the total sample, $67.7 \%$ were identified to have high acculturation. On the logistic regression model, $\geq 10$ years stay in the US ( $p=0.0068)$, cholesterol level $\geq 200 \mathrm{mg} / \mathrm{dl}(\mathrm{p}=0.0002)$, BMI $\geq 23(p=0.0044)$ and family history of CAD $(p=0.0078)$ were found to be independent predictors of CAD. Similar results were seen with $\mathrm{T} 2 \mathrm{D}$ as an outcome. Those with high CAD had 2.11 (CI 1.32 to 6.68 ) odds of having total cholesterol $\geq 200 \mathrm{mg} / \mathrm{dl}$ compared to those without CAD.

Conclusions Acculturation plays a major role in predisposing immigrant population to CAD. There is need for developing tools that consider acculturation as a predictor for CAD. Further studies that test tailored strategies to improve lifestyle behaviours across diverse racial/ethnic groups of immigrants are needed. 